\title{
Seasonality of Tropical Photosynthesis: A Global Map of Drivers and Comparison to Model Outputs
}

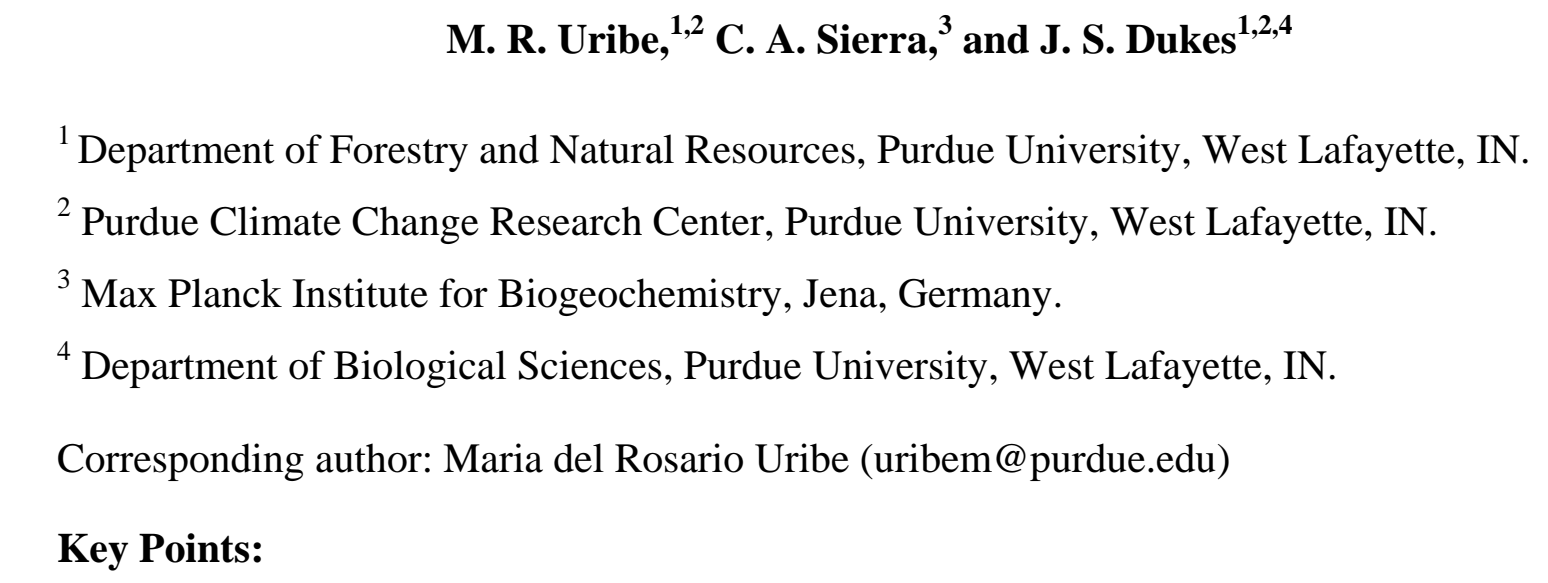

${ }^{1}$ Department of Forestry and Natural Resources, Purdue University, West Lafayette, IN.

${ }^{2}$ Purdue Climate Change Research Center, Purdue University, West Lafayette, IN.

${ }^{3}$ Max Planck Institute for Biogeochemistry, Jena, Germany.

${ }^{4}$ Department of Biological Sciences, Purdue University, West Lafayette, IN.

Corresponding author: Maria del Rosario Uribe (uribem@purdue.edu)

\section{Key Points:}

- In tropical ecosystems, photosynthetic activity responds strongly to seasonal variation in water and light.

- In most regions, photosynthesis varies with seasonal fluctuations in both resources, but relationships with a single driver are also common.

- The relationship of climate with photosynthetic activity is characterized by water availability and its synchronization with light.

- Land surface models overestimate the extent of positive correlations with water and underestimate those with light.

- The relationships of photosynthetic activity with climate identified from remote sensing data closely agree with global datasets such as VPM and GOSIF. 


\begin{abstract}
Tropical ecosystems strongly influence Earth's climate and weather patterns. Most tropical ecosystems remain warm year-round; nonetheless, their plants undergo seasonal cycles of carbon and water exchange. Previous research has shown the importance of water and light as drivers of the seasonality of photosynthetic activity in the tropics. Although data are scarce, field-based studies have found that seasonal cycles at a handful of tropical forest sites do not match those in land surface model simulations. A comprehensive understanding and model comparison of how seasonal variations in tropical photosynthetic activity relate to climate is lacking. In this study, we identify the seasonal relationships of precipitation and light availability with satellite-based photosynthetic activity. Three dominant and spatially distinct seasonal relationships emerge between photosynthetic activity and these two environmental drivers: photosynthetic activity that is positively correlated with both drivers (36\% of tropical pixels), activity that increases following rain but decreases with light (28\%), and activity that increases following bright seasons but decreases with rain (14\%). We compare distributions of these observed relationships with those simulated by land surface models. In general, model simulations of gross primary productivity (GPP) overestimate the extent of positive correlations of photosynthetic activity with water and underestimate positive correlations with light. The largest discrepancies between simulations and observations are in the representation of the regions where photosynthetic activity increases with light and decreases with rain. Our clear scheme for representing the relationship between climate and photosynthetic activity can be used to benchmark tropical seasonality of GPP in land models.
\end{abstract}

\title{
Plain Language Summary
}

Tropical ecosystems strongly influence Earth's atmosphere and climate through their high rates of photosynthesis and transpiration. These rates vary seasonally, but tropical seasonal cycles and their drivers are incompletely characterized. Here, we identify and characterize the three most common relationships between seasonality of photosynthetic activity and two main climatic drivers, water and light. Each type of relationship is associated with specific climate properties. In short, when seasonal cycles of water and light are synchronized, vegetation responds positively to both drivers. When the cycles are not synchronized, drier sites respond positively to water and negatively to light, while wetter sites respond positively to light and negatively to water. Ecosystem models generally lack the mechanisms that lead to this latter relationship. Our improved understanding of these relationships can guide model improvement efforts for tropical ecosystems.

\section{Introduction}

Tropical ecosystems are sometimes called the "lungs of the planet," because their high photosynthetic rates drive large fluxes of carbon and water. Tropical forests alone account for about $60 \%$ of global terrestrial photosynthesis (Mitchard, 2018) and influence precipitation patterns, even at the continental scale (Lawrence \& Vandecar, 2015). Collectively, tropical ecosystems disproportionately influence Earth's climate and weather patterns (Malhi et al., 2008).

At the intra-annual or seasonal scale, climate patterns determine ecosystems' metabolism, phenological patterns, and vegetation distribution. Ecosystem metabolism, in turn, affects the climate system through photosynthesis and the associated carbon, water, and energy feedbacks to 
the atmosphere. But this ecosystem-atmosphere interaction is being altered by ongoing changes in the climate system. Forecasting the effects of these climatic changes on tropical ecosystems, and the subsequent consequences for biosphere-atmosphere interactions and climate at regional and global scales requires accurate estimates of current photosynthetic rates in tropical ecosystems and an understanding of their relationship with climate. While photosynthetic rates go through clear and well-understood seasonal cycles in temperate regions, seasonality of photosynthesis in the tropics is less well understood (Wu et al., 2016). Across most ecosystems in these consistently warm regions, both the patterns of seasonality and the drivers of those patterns remain largely uncharacterized (Restrepo-Coupe et al., 2017; Saleska et al., 2003).

Marked seasonal patterns in vegetation activity, although sometimes weaker or less defined in comparison to those of the temperate zones, have been observed in both field- and satellite-based measurements in the tropics. Estimates from eddy covariance towers show strong seasonal patterns in net ecosystem exchange and gross primary productivity (GPP) in most sites where data are available (Restrepo-Coupe et al., 2013; Saigusa et al., 2008). Such sites include tropical rain forests and savannas from the Amazon and Asia. Satellite-based measurements of proxies of phenology and photosynthetic activity such as leaf area index (LAI), enhanced vegetation index (EVI) and solar-induced fluorescence (SIF), often show similar seasonal patterns to those observed in the field (Bertani et al., 2017; Bradley et al., 2011a; Guan et al., 2015; Myneni et al., 2007; Xu et al., 2015). These studies demonstrate that seasonality extends across the tropics, with only a small portion of the region not showing any type of seasonality.

Land surface models, however, are unable to characterize the observed seasonal cycles, as shown for some specific sites in the Amazon (Restrepo-Coupe et al., 2017). At individual study sites, models simulate either constant GPP or opposite seasonal patterns to the ones observed in the field (Restrepo-Coupe et al., 2017). Yet, these models are a major component of Earth System Models (ESMs) and constitute the main tool scientists currently rely on for future projections of climate, ecosystems and their interrelationship. Models that represent seasonal cycles in the tropics more accurately would be able to estimate how changes in climate seasonality (e.g., timing or length of wet and dry seasons) could affect intra-annual carbon fluxes and, subsequently, the annual carbon budgets of tropical ecosystems (Saleska et al., 2003). Accurate simulation of terrestrial water cycling, including the effects of tropical vegetation on regional to global precipitation patterns, also depends on realistic simulations of photosynthetic activity.

In order to accurately represent the seasonality of tropical photosynthetic activity in land surface models, we need to understand the climatic drivers of this seasonality. This involves recognizing how they vary from one region in the tropics to another, and the potential mechanisms and delayed responses involved in the climate-vegetation relationship. Water and light availability are the main drivers of intra-annual variation in vegetation activity in the tropics, and within the region there is wide variation in the responses to these two drivers (Nemani et al., 2003; Seddon et al., 2016). Previous studies attribute the regional differences in vegetation seasonality to water stress (Guan et al., 2015; Wagner et al., 2017). In this sense, photosynthetic activity follows precipitation cycles in drier ecosystems, such as pastures, deciduous forests or degraded forests (Bradley et al., 2011a; Huete et al., 2006). In ecosystems with higher mean annual rainfall or a shorter dry season, like evergreen forests, photosynthetic activity is either less seasonal or more closely associated with light availability (Guan et al., 2015; Nemani et al., 2003). The mechanisms leading to these different vegetation-climate 
relationships are still being studied and, therefore, are more challenging to represent in land surface models. Moreover, it is common for the relationship of photosynthetic activity with climate to be lagged depending on the climatic factor and vegetation types (Bradley et al., 2011a; D. Wu et al., 2015). Identifying the importance of these lagged correlations in different parts of the tropics can also guide future research and inclusion of underlying mechanisms in models.

Despite the large variation in seasonal patterns across the tropical region and the discrepancy found between GPP from field measurements and models, most satellite-based studies of tropical vegetation seasonality have focused on the Amazon basin. Moreover, model performance has only been tested at the site level, also within the Amazon. A global analysis of the drivers of photosynthesis seasonality in the tropics and how they differ in models would unveil large-scale patterns. These discoveries could help experiments and models target weakly represented regions and ecosystems. Here, we investigated how the seasonality of photosynthetic activity across the entire tropical region relates to the two most important regional-level climate drivers; precipitation and radiation. These two variables also provide the main forcing data used by land surface models to simulate most vegetation processes. In contrast to previous studies, rather than identifying a single climate predictor of photosynthetic activity, we sought to characterize its relationship (including direction and magnitude) with both precipitation and radiation. This approach allowed us to identify where in the tropics photosynthesis is positively or negatively associated with each of the two climate drivers, including lagged responses to these drivers. We then identified the climatic variables most commonly associated with each of the various relationships between photosynthesis and the climatic drivers. We expected annual precipitation and variability to explain the relationship with both water and light; for instance, photosynthetic activity in extremely wet regions should be positively correlated with light and negatively correlated with water. In arid regions, photosynthetic activity should be positively correlated with water and negatively correlated with light. In regions that are neither extremely wet nor dry, and with more evenly distributed precipitation throughout the year, we expected photosynthesis to be positively correlated with both water and light. We compared results from remote sensing data with three ecosystem models and two commonly used GPP datasets. We expected the most widespread pattern in these models and datasets to be a positive relationship between photosynthetic activity and water and a negative relationship with light. 


\section{Materials and Methods}

2.1 Climate data

Monthly mean precipitation and net radiation were retrieved for the period 2000-2017. Precipitation was obtained from the TRMM (TMPA/3B43) Rainfall V7 product with a spatial resolution of 0.25 -degree $x$ 0.25-degree (TRMM, 2011). This product is the best estimate of an algorithm that uses multi-satellite data from two instruments, the Precipitation Radar and the TRMM Microwave Imager (Huffman et al., 2007). Data of incoming shortwave radiation at the surface were obtained from the Energy Balanced and Filled (EBAF) Surface data product Edition 2.8 from the NASA Clouds and the Earth's Radiant Energy System (CERES) experiment at a 1-degree x 1-degree spatial resolution (Loeb et al., 2009). This product is the output of radiative transfer models that use a series of satellite-based observations of top-of-atmosphere radiation and cloud physical and radiative properties to calculate the surface data (Kato et al., 2013).

For the characterization of site-specific climate variables, we calculated MAP, mean radiation, mean temperature, mean dry-season length, and precipitation seasonality index. All of the climate variables correspond to the average for the period 2000-2016 for each pixel. MAP and mean radiation were estimated using the datasets above. Mean temperature was estimated for the period of study from the Climatic Research Unit (CRU) Time-Series (TS) Version 4.02 of High-Resolution Gridded Data of Month-by-month Variation in Climate (Harris et al., 2014). The data are in a $0.5 \times 0.5$-degree grid and are produced based on observational data from national and external meteorological agencies. Dry-season length was obtained from the Rainy and Dry Seasons (RADS) dataset (Bombardi et al., 2019). This dataset uses global gridded daily precipitation datasets to provide several characteristics of precipitation seasonality at $0.25-\mathrm{x}$ 0.25-degree spatial resolution. In RADS, seasons are calculated at the local scale based on the accumulated precipitation anomalies of each grid point. Accumulated precipitation anomalies are calculated by comparing daily precipitation against the long-term mean daily precipitation. Calculations of the accumulated anomalies start every year in the dry season, which is estimated as the first minimum harmonic of the precipitation mean annual cycle. The start and end of the wet and dry seasons correspond to inflection points in the accumulated anomalies curve for each cycle. More details of the algorithm and assumptions for these calculations are provided in Bombardi et al. (2019). The precipitation seasonality index was calculated using the Walsh and Lawler equation (Walsh \& Lawler, 1981). This index uses the total annual and monthly precipitation for each year within the period of study to characterize the distribution of precipitation throughout the year. Small values indicate less seasonality or equal distribution of the precipitation throughout the year, while higher values indicate higher concentration of precipitation in fewer months.

While some areas of the tropics underwent extensive changes in land cover during the study period (Hansen et al., 2013), the models in this study used static land cover data. Because of the contrast between the coarse resolution of the data used here and the fine resolution at which land cover change occurs, we were unable to include this information in our analyses. The effects of land cover change on seasonality of tropical GPP and its response to precipitation and radiation should be examined in future studies. 
We used three independent datasets to estimate photosynthetic activity in this study. Two of these were satellite-based proxies: Solar Induced Fluorescence (SIF) and the Multi-Angle Implementation of Atmospheric Correction Enhanced Vegetation Index (MAIAC EVI). The third is a remote sensing-derived product based on SIF, known as GOSIF. SIF data came from the GOME2_F data products V27 (Level 3) (https://avdc.gsfc.nasa.gov/pub/data/satellite/MetOp/GOME_F/, accessed on April 2018) (Joiner et al., 2013). This SIF monthly dataset is available at $0.5 \times 0.5$-degree resolution since 2007 . The GOSIF dataset is based on SIF retrievals from OCO-2 in addition to a predictive model and other MODIS remote sensing and meteorological reanalysis datasets (http://data.globalecology.unh.edu/data/GOSIF/, accessed on March 2019) (Li \& Xiao, 2019). GOSIF is available monthly at 0.05 x 0.05 -degree resolution since 2000. MAIAC EVI was obtained from calibrated and geometrically corrected MODIS Collection 6 Level 1B satellite images (https://portal.nccs.nasa.gov/datashare/maiac/DataRelease/Global-VI-8day-0.05degree/, accessed on September 2018) (A. Lyapustin et al., 2018). The monthly MAIAC EVI product is at $0.05 \times 0.05$-degree resolution and since 2000.

Each of the satellite-based vegetation datasets has advantages and disadvantages. SIF data from the Global Ozone Monitoring Experiment-2 on MetOp-A and -B (GOME 2) should represent photosynthetic activity well, but the temporal period available, from 2007 to 2018 is not an ideal match with available model output, and sensor degradation for GOME-2 has been a concern (Zhang et al., 2018). GOSIF data, developed from Orbiting Carbon Observatory-2 (OCO-2) measurements, should approximate the SIF data and covers a longer period, from 2000 to 2018. However, the derived data in the GOSIF product are more removed from the direct observations than SIF. MAIAC EVI has a similarly long time series as GOSIF and has been frequently used in tropical ecosystem studies; it has proved to be a better proxy of photosynthetic activity in tropical rainforests than other vegetation indices such as Normalized Difference Vegetation Index (NDVI) or MODIS EVI (Maeda et al., 2016). However, MAIAC EVI is still a vegetation index that estimates vegetation greenness and not photosynthetic activity directly, which is more accurately estimated with SIF (Joiner et al., 2011).

Both the SIF and MAIAC EVI datasets have undergone an advanced cloud screening and filtering process, which has made them advantageous to use in the tropics compared to other remote sensing products. In SIF, the main problem of clouds for SIF retrievals is a shielding effect, as, contrary to vegetation indices, the SIF spectral signature is not affected by clouds (Joiner et al., 2014). Therefore, in the SIF dataset used here, cloud filtering is done by removing pixels with effective cloud fractions of $>30 \%$. This filter threshold has been proved to maintain spatial and temporal patterns of SIF without altering the sample size and the noise resulting from reduced coverage (Joiner et al., 2013). MAIAC EVI has a sophisticated cloud and aerosol screening correction algorithm. In this later product, pixels with atmospheric contamination are not excluded from the dataset and are not included in our study (A. I. Lyapustin et al., 2012). As part of our time series analysis, we filled data gaps of a maximum of three months using spline interpolation. Pixels with gaps longer than three months in the time series were excluded from the analysis.

\subsection{Modeled GPP}

To examine tropical seasonality exhibited in land surface models (LSMs), simulated GPP data were obtained from the TRENDY (Trends and drivers of the regional scale sources and 
sinks of carbon dioxide) project (Sitch et al., 2015). Most TRENDY models are LSMs commonly coupled with ESMs and used for climate projections. Here, we used TRENDY v5 S2 simulations from CLM4.5 (Oleson et al., 2013), JULES (Best et al., 2011), and LPJ-GUESS (Smith et al., 2001). In TRENDY, each model is run globally with different spatial scales and land cover types, but with the same forcing data. Land cover data for the simulations is fixed and provided by each modeling group. In addition to the LSM-simulated GPP, two global GPP products, Fluxcom (Jung \& Team, 2016; Tramontana et al., 2016) and VPM (Zhang et al., 2017), were also analyzed. These datasets are derived using field observations, satellite-based measurements, and reanalysis meteorological data, in combination with interpolation or machine learning techniques. The final products are global-scale gridded GPP estimates with long temporal coverage and high spatial resolution (see Table S1 for details).

\subsection{Data analysis}

We used time series analysis to identify relationships between climate variables (i.e., precipitation and radiation) and various estimates of photosynthetic activity (i.e., SIF, GOSIF, MAIAC EVI, and simulated GPP) across the entire tropics. We used cross-correlation function (CCF) analysis (Box et al., 2015), to examine time series of monthly data for each pixel in the tropics $\left(20^{\circ} \mathrm{N}-20^{\circ} \mathrm{S}\right)$ from 2000 to 2015 (except SIF and GOSIF, which were analyzed for 20072017 and 2000-2017, respectively). Although the SIF dataset covered different years than the other datasets, the 11 years of SIF data provide a robust basis for our seasonal analyses, and the SIF analyses can be broadly validated with the longer and independent GOSIF dataset. We excluded from all analyses all pixels with a mean EVI of less than 0.1. Those low EVI pixels, which correspond to barren lands or extremely low vegetation cover, were removed to avoid noise in the photosynthetic activity data and the subsequent calculations. Prior to the analysis, each pair of climate and photosynthetic activity variables was resampled to a common spatial resolution in order to enable time series analysis at the pixel level.

We used CCF analysis to calculate direct (i.e., same month) and lagged correlations between each climate variable (i.e., independent variable) and each photosynthetic activity variable (i.e., response variable). We quantified lagged correlations between one and four months because a variety of physiological and ecological mechanisms can potentially delay responses of photosynthetic activity to climate (D. Wu et al., 2015). Our lagged correlations analysis allowed us to determine the strongest immediate or lagged correlation between precipitation or radiation and photosynthetic activity.

In CCF analysis, temporal dependencies or high autocorrelation in the independent variable (in this case our climate variables) can hide true relationships or suggest false ones. "Prewhitening" can remove autocorrelations by extracting the "white noise" from the independent variable and applying the same transformation to the response variable, in this case, photosynthetic activity (Cryer \& Chan, 2008). We used prewhitening to counteract autocorrelation, allowing us to analyze the actual linear relationship between the two time series. The data were pre-whitened by first finding an autoregressive integrated moving average (ARIMA) model for the climate variable time series, and then fitting the photosynthetic activity time series to the ARIMA model. ARIMA models are built using information contained in the time series and are commonly used in forecasting, but in the case of this study, and prewhitening in general, they are used to filter the original series. The CCF was finally performed on the climate series model residuals and the filtered photosynthetic activity time series (Box et al., 
2015; Probst et al., 2012). An example of the CCF analysis is available at https://github.com/rosariouribed/ccf_tropics.

Given that precipitation and radiation are two highly correlated variables, we were interested in an analysis that considered the relationship of photosynthetic activity with the two variables individually and in combination. We determined the sign of the maximum direct or lagged correlation coefficient with each variable and then classified the type of relationship based on the signs and strengths of the two coefficients. For instance, photosynthetic activity could be correlated positively with precipitation and negatively with radiation or have a nonsignificant relationship with precipitation and positive with radiation, and so on (Fig. 1, upperright reference panel). We created a map for each of the photosynthetic activity datasets showing the type of relationship with climate for each pixel. We assessed the agreement between the results from satellite and model data using the Kappa coefficient ( $\kappa$ ) for map agreement (Cohen, 1960). The Kappa coefficient compares the agreement between two maps against a hypothetical scenario of randomly assigned values. Coefficients range from -1 to 1 , where 0 indicates that the evaluated map is as good as if random values were selected, negative values suggest the map is worse than random values, and positive values suggest the evaluated map matches the reference map better than random values. Values closer to 1 indicate a better agreement between the maps. We also calculated the overall difference $(D)$ as a second measurement of agreement of our results. Overall difference has been suggested to provide a more reliable comparison between maps than the Kappa coefficient (Pontius \& Santacruz, 2014). Calculations of $D$ take into account how well maps agree on (1) the number of pixels classified in each category (i.e., quantity difference) and (2) the location of the pixels in each category, given the number of pixels in each of the categories (i.e., allocation difference) (Pontius \& Santacruz, 2014). Larger $D$ values indicate greater disagreement between the maps, either because of under- or overestimation of pixels in the different categories, or because of inaccurate spatial allocation of the pixels in each of the categories. Comparisons between maps were also performed at the biome level in order to identify models' biome-specific shortcomings.

We then used the classification of type of relationship and additional climate properties of each pixel to identify climate properties most closely associated with a specific type of relationship. Only the most common types of relationships (i.e., more than $10 \%$ of the pixels) were included in the comparison.

The additional climate properties included MAP, mean radiation, mean temperature, dry season length, precipitation seasonality index, and the correlation between monthly precipitation and radiation. We used Kruskal-Wallis nonparametric tests (Kruskal \& Wallis, 1952) to identify significant differences in the climate properties among the type of relationships. If the KruskalWallis result was significant $(\alpha=0.05)$ for a particular variable, we followed up with a pairwise comparison among all types of relationships through the Dunn test with Bonferroni correction (Dunn, 1964). This nonparametric post hoc test can be used for independent groups with nonnormal distributions and different sizes. All analyses were performed in R 3.4.0 (R Core Team, 2017), including the forecast v8.2 (Hyndman, 2017), TSA v1.01 (Chan \& Ripley, 2012), FSA v0.8.22 (Ogle et al., 2018) and diffeR (Pontius Jr. \& Santacruz, 2019) packages. 

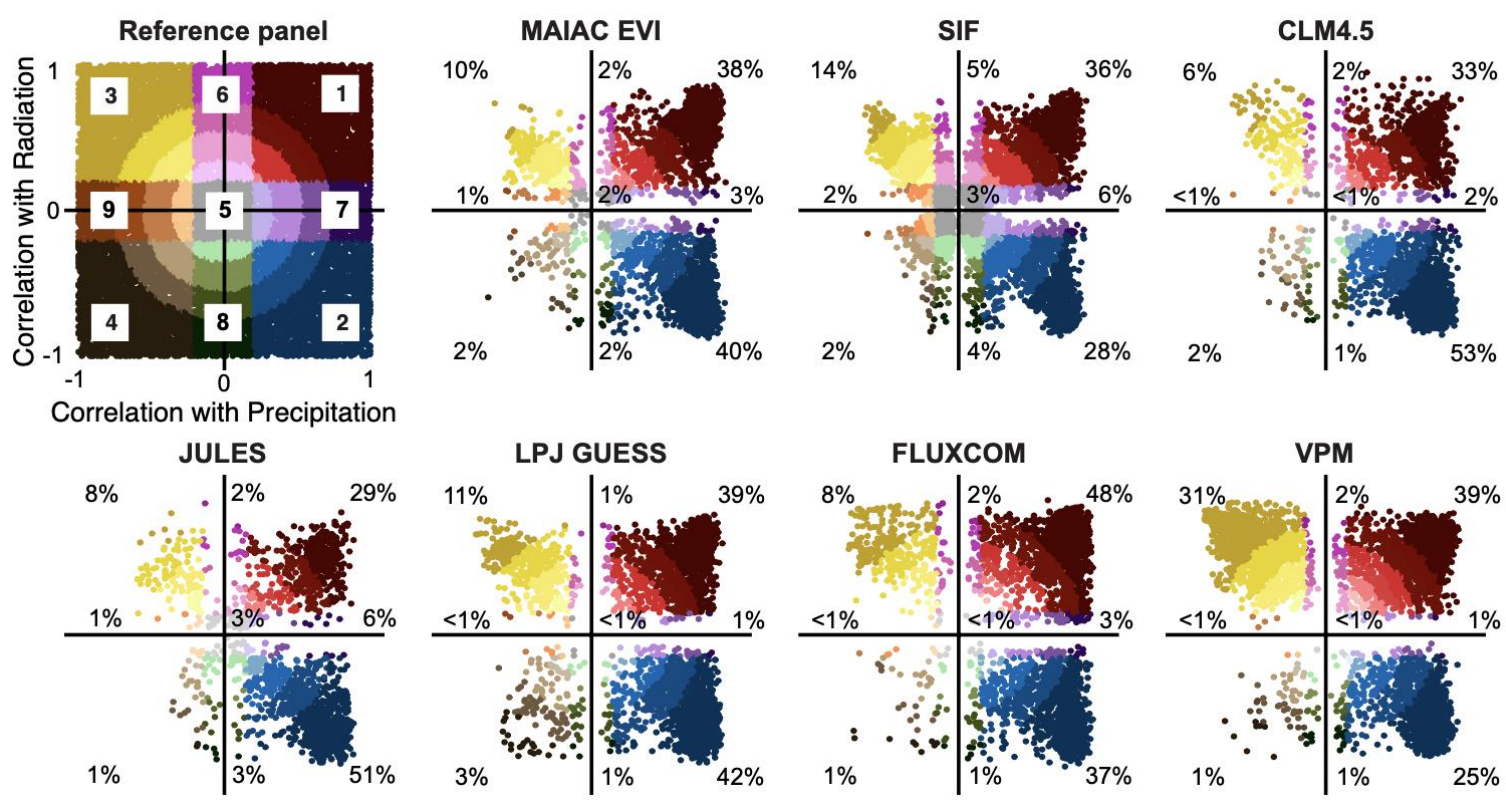

Fig. 1. Scatterplots showing the maximum correlation coefficient from the CCF analysis for vegetation productivity from each of the datasets with precipitation (x axis) and radiation (y axis). (Top-left/Reference panel): the nine colors and numbers correspond to each of the types of relationships; the rings indicate the strength of the correlation with both drivers (distance from the origin). Regions 1-4 (red, blue, yellow, and brown) indicate significant correlations with both drivers. Region 5 (gray color) indicates non-significant relationships with any driver. Regions 69 (pink, purple, green, and orange indicate non-significant correlations with one of the drivers. (Other panels): the numbers indicate the percentage of pixels with the type of relationship where the number is located.

\section{Results}

data

3.1 Relationship of photosynthetic activity with precipitation and radiation in satellite

Based on the direction of the correlations between photosynthetic activity and the two climate drivers, most sites in the tropics can be classified into three categories, with photosynthetic activity that is either (1) positively correlated with both precipitation and radiation, (2) positively correlated with precipitation but negatively correlated with radiation, or (3) positively correlated with radiation but negatively with precipitation (i.e., regions 1, 2 and 3 in Fig. 1 upper-left reference panel). Hereafter, we refer to these three types of relationships as cosynchronous, rain-following and light-following, respectively. For MAIAC EVI and SIF, these three types of relationships together account for 78-88\% of tropical pixels, where the cosynchronous pixels correspond to $36-38 \%$, the rain-following $28-40 \%$ and the light- following $10-14 \%$ of pixels for the two datasets, respectively (Fig. 1). Examples of the seasonal patterns of precipitation, radiation and photosynthetic activity from SIF in pixels from the three main types of relationships are displayed in the Supplementary Materials (Fig. S1). While both datasets agree on the dominance of these three types of relationships, there are some differences between the two datasets in the proportion of pixels that show each of these three dominant types (Fig. 1). In the SIF dataset, more pixels are cosynchronous and light-following and fewer are rain- 
following than in the MAIAC EVI product. The spatial distribution of the three types of relationships is moderately consistent between the two datasets, with a kappa coefficient of agreement of 0.5 and overall difference of $35.12 \%$ (Table 1, Fig. 2). The results from GOSIF agree closely with those from SIF and EVI $(\kappa=0.52$ and $0.65, \mathrm{D}=33.42$ and $22.58 \%$, respectively), providing stronger confidence in our results (Fig. S2).

Based on the SIF results, cosynchronous pixels (i.e., positive correlations with both precipitation and light) are located across all biomes, but make up the largest fraction (45-86\%) of savannas and shrublands, dry broadleaf forests, flooded savannas, montane shrublands, and conifer forest (Fig. S3). The rain-following relationship (28\% across all biomes) is most common in savannas and shrublands, dry forests, flooded savannas, and xeric shrublands. Light-following seasonality is mostly clustered in rainforests, specifically those of the Amazon basin and southeast Asia.

Other types of relationships are not common ( $<22 \%$ in total), but include negative correlations with both drivers ( $<3 \%$ of pixels) and weak correlations with one ( $<6 \%$ of pixels) or both ( $<3 \%$ of pixels) drivers. For the SIF dataset, these other types of correlations occur mostly in the rainforest in South America, central Africa and southeast Asia. A more detailed look at areas with the weakest relationships shows a prevalence of pixels with very low intra-annual variability in photosynthetic activity. These less distinct types of relationships could also be explained by a higher diversity of vegetation cover or land cover change during the study period.

The seasonal peak of photosynthesis most commonly occurred within two months of the seasonal peak of precipitation, while lags with radiation had a much wider range of variation, from 0 to 4 months (Fig. 3, Fig. S4). These lags also varied among the types of relationships. In regions with a cosynchronous relationship, peaks of photosynthesis typically followed peak precipitation by 0-2 months, and peak radiation by 3-4 months (Fig. 3, Fig. S4a). In regions with a rain-following relationship, photosynthetic activity lagged peaks of precipitation (and lows of radiation) by 0-2 months (Fig. 3, Fig. S4b). In regions with a light-following relationship, photosynthetic peaks lagged minimum precipitation by a wide range of $0-4$ months, and commonly lagged radiation peaks by 0 to 3 months, although with large variation (Fig. S4c). The relatively few pixels that have the longer time lags with precipitation occur in the tropical rainforests of South America, which is mostly a light-following region. A large proportion of the longer time lags with radiation coincides with cosynchronous regions in the higher tropical latitudes of Africa and Australia.

3.2 Climate properties of the different types of relationships of photosynthetic seasonality with precipitation and radiation

Each of the three dominant climate-seasonality relationships was associated with distinct climatic properties (Fig. 4A-E). Areas with a cosynchronous relationship tended to have relatively low annual rainfall (Median $=1217$ and Interquantile Range $=26 \mathrm{~mm}$ ), high mean daily radiation $\left(\tilde{\mathrm{x}}=227.9\right.$ and $\left.\mathrm{IQR}=1.12 \mathrm{~W} \mathrm{~m}^{-2}\right)$, a long dry season $(\tilde{\mathrm{x}}=221.9$ and $\mathrm{IQR}=1.4$ days), relatively low mean temperature $\left(\tilde{\mathrm{x}}=25.7\right.$ and $\left.\mathrm{IQR}=0.1{ }^{\circ} \mathrm{C}\right)$, and high rainfall seasonality $(\tilde{\mathrm{x}}=0.8$ and $\mathrm{IQR}=0.01)$. Rain-following pixels had low MAP $(\tilde{\mathrm{x}}=1214$ and $\mathrm{IQR}=24 \mathrm{~mm})$, 


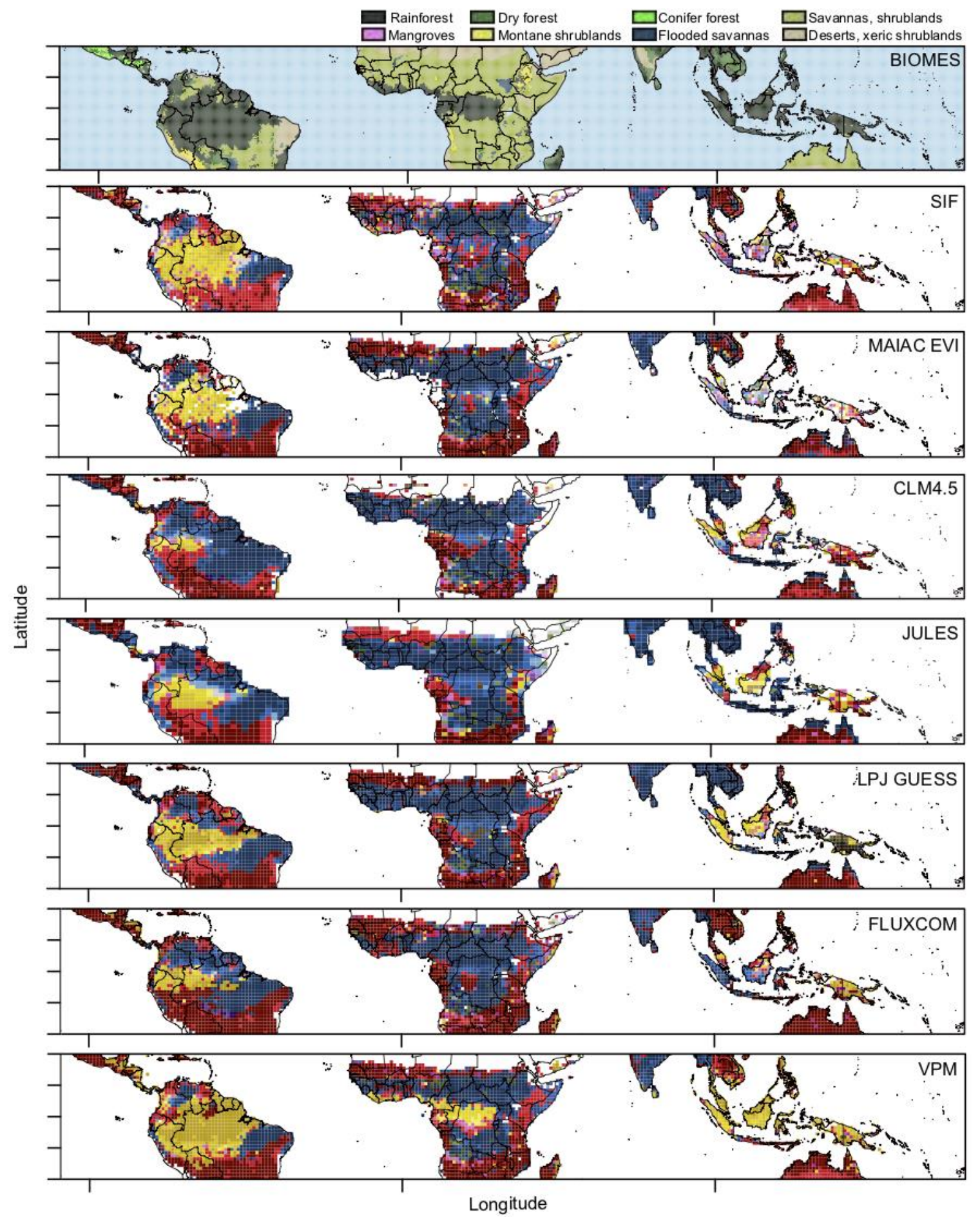

382 Fig. 2. Maps of biomes and results from the CCF analysis. (Top panel): biomes of the tropics (WWF). (Other panels): Maps showing the spatial distribution of the maximum correlation coefficient from the CCF analysis for vegetation productivity from each of the datasets with precipitation and radiation. Colors in the map correspond to the colors and numbers in the reference panel Fig. 1, which contain information about the type of combined relationship and strength of the correlations. White pixels correspond to water bodies or pixels with scarce data for CCF analysis. 
high mean daily radiation $\left(\tilde{\mathrm{x}}=227.9\right.$ and $\left.\mathrm{IQR}=0.9 \mathrm{~W} \mathrm{~m}^{-2}\right)$, an intermediate-length dry season $(\tilde{\mathrm{x}}$ $=203.1$ and $\mathrm{IQR}=1.6$ days), higher mean temperature $\left(\tilde{\mathrm{x}}=26.1\right.$ and $\left.\mathrm{IQR}=0.1^{\circ} \mathrm{C}\right)$, and intermediate rainfall seasonality $(\tilde{\mathrm{x}}=0.8$ and IQR $=0.01)$. Light- following pixels had high MAP $(\tilde{\mathrm{x}}=2466$ and IQR $=40 \mathrm{~mm})$, low mean daily radiation $\left(\tilde{\mathrm{x}}=201.5\right.$ and $\left.\mathrm{IQR}=0.7 \mathrm{~W} \mathrm{~m}^{-2}\right)$, a short dry season $\left(\tilde{\mathrm{x}}=189.9\right.$ and $\mathrm{IQR}=1.1$ days), high mean temperature $\left(\tilde{\mathrm{x}}=26.4\right.$ and $\left.\mathrm{IQR}=0.1{ }^{\circ} \mathrm{C}\right)$, and low precipitation seasonality $(\tilde{\mathrm{x}}=0.5$ and $\mathrm{IQR}=0.01)$. The climates of areas with the lightfollowing relationship stood out as distinct from those in other areas across four of the five variables - only temperature, by not differing from regions with the rain-following relationship, opposed this trend. Cosynchronous and rain-following pixels had similar MAP and mean daily radiation, but cosynchronous pixels had a longer dry season, lower mean temperature, and larger precipitation seasonality index.

The correlation between precipitation and radiation also provided meaningful information about the relationship between photosynthetic activity and climate. In areas with a cosynchronous relationship, light and precipitation typically were abundant during the same or similar times of year (Fig. 4F). In these areas, photosynthesis was greatest during the times of year that were both wet and bright. In contrast, in areas with the other two dominant types of relationships, the rainiest times of year were the darkest, and the driest seasons were brightest. In these areas, GPP responded most positively to the climate factor that was most limiting. Thus, areas that have lower MAP and a longer dry are water-limited and showed a positive correlation with rainfall, and consequently a negative correlation with radiation. In areas with higher MAP

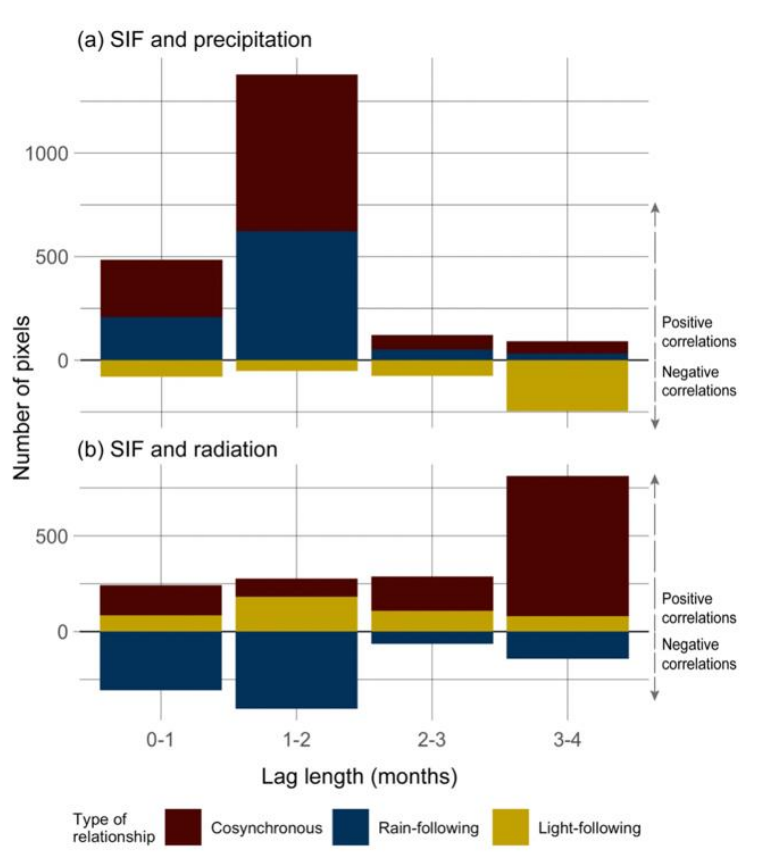

Fig. 3. Frequency (number of pixels) of the length of lags in the strongest correlations between SIF and (a) precipitation and (b) radiation for the three most common types of relationships $(n=2533)$. Colors correspond to the colors of the types of relationships shown in the reference panel in Fig. 1. In order to differentiate the direction of the correlation, the count of pixels with positive correlation coefficients between the climate driver and SIF is shown upward and the count with negative correlation coefficients is shown downward. Note the difference in scales between (a) and (b). 

Fluxcom (Table 1). Similar to the satellite observations, the model most similar to these two GPP products was LPJ-GUESS.

In our biome-level comparisons (Table S2), the best agreement between SIF and most models was found in montane grasslands and shrublands $(\kappa=0.46-0.57, \mathrm{D}=18-25 \%)$, flooded grasslands and savannas $(\kappa=0.38-0.44, \mathrm{D}=28.6-34.2 \%)$, and grasslands and savannas $(\kappa=$ $0.33-0.46, \mathrm{D}=30.7-41.8 \%)$, in that order. In contrast, low agreement was found in mangroves $(\kappa$ $=-0.17-0.28, \mathrm{D}=52.2-72.7 \%)$, rainforest $(\kappa=0.19-0.34, \mathrm{D}=45.4-62.7 \%)$ and deserts and xeric shrublands $(\kappa=0.12-0.33, \mathrm{D}=31.5-41.5 \%)$. In dry forests, Fluxcom and VPM showed closer agreement with SIF than the land surface models did.

\section{Discussion}

Our results identify three primary relationships between photosynthetic activity and seasonal patterns of water and light availability across the entire tropical region. In addition to mapping these patterns, our classification provides a clear scheme for model comparison. Finally, the analysis shows where, and for which climate variables, lagged correlations occur and need to be accounted for in ecosystem models.

Previous research has shown the importance and the spatial distribution of water and light as drivers of photosynthetic activity at the seasonal scale in the tropics (Guan et al., 2015; Nemani et al., 2003; Seddon et al., 2016). Our results are in agreement with those studies; we found the prevalence of positive correlations (1) with water in most of the drier regions in the tropics and (2) with light in the wet tropical forests. In addition to finding these positive correlations, we also considered negative correlations with each driver as part of our analyses. These results revealed that a positive correlation with one driver does not necessarily imply a negative correlation with the other driver, particularly when both climate variables are highly correlated with each other. In fact, positive correlations with both drivers, a cosynchronous relationship, is the most common type of relationship in the tropics.

The cosynchronous relationship is mainly found in regions with a low MAP, high mean daily radiation, long dry season, and high precipitation seasonality. These regions correspond to water-limited biomes located in higher latitudes where precipitation and radiation are not negatively correlated, meaning water and light are abundant at approximately the same time. Rain-following relationships are found in regions with similar precipitation and radiation characteristics and are also common in similar biomes. However, this relationship is more common at lower latitudes where precipitation and radiation are negatively correlated. Vegetation from cosynchronous and rain-following regions is likely water-stressed for part of the year, and therefore responds positively to water availability. What differentiates the regions with these two types of relationships is the timing of radiation with respect to precipitation. In the cosynchronous relationship, vegetation is adapted to take advantage of seasonal availability (up to 4 months) of both water and light. In the rain-following relationship, vegetation is adapted to periods of increased rainfall that do not coincide with the most abundant light.

The third most common type of relationship, the light-following relationship, is found in regions with high MAP, low mean daily radiation, a short dry season, low precipitation seasonality, and a negative correlation between precipitation and radiation. This relationship and climate characteristics are very specific to the rainforests of South America where previous field (Restrepo-Coupe et al., 2013; Saleska et al., 2003) and satellite (Bertani et al., 2017; Bradley et 
al., 2011b; Wagner et al., 2017) findings show light-driven seasonal photosynthetic activity. Similarly, the spatial distributions of the rain- and light- following relationships found here are comparable to the wet- and dry-season greening regions for tropical rainforests, with those forests in the central Amazon and southeast Asia greening in the dry season, when radiation peaks (Doughty et al., 2019; Guan et al., 2015).

The mechanisms by which plant species have adapted to (or been selected by) seasonal fluctuations in precipitation and light could determine vegetation responses to any future changes in these patterns. Recognizing the specific correlation of photosynthetic activity in these regions with the availability of water and light may lead to studies that identify relevant adaptive traits and selective processes, and to better-informed predictions.

Rather than establishing direct causality between water, light, and photosynthetic activity, we explored the nature of observed relationships. The widespread lagged correlations identified here should guide experimental and mechanistic representation of photosynthetic activity. These lagged correlations are consistent with analyses of Bradley et al. (2011) and Wu et al. (2015). The observed time lags suggest that responses of vegetation to rain and light are influenced by intermediate or indirect processes. Enhanced vegetation growth and leaf development may continue long after after the seasonal peaks in delivery of water or light, such that the ecosystem reaches maximum biomass of leaves, or of the most photosynthetically-efficient leaves, later in the season (Duff et al., 1997; Rivera et al., 2002; J. Wu et al., 2016). This continued growth could cause delayed peaks in photosynthetic activity relative to resource delivery. We found a high frequency of lagged correlations in cosynchronous regions, where correlations with precipitation were strongest for short time lags, but correlations with radiation tended to be strongest after longer lags. The longer radiation lags mostly occur in the higher tropical latitudes. We speculate that this delayed correlation is the result of plant growth and leaf development continuing throughout the summer season (i.e., continuing after peak radiation), with increased precipitation later in the season leading to a spike in photosynthetic activity. However, phenology and increase in foliage can be highly variable in tropical ecosystems, even within the same biome (Bie et al., 1998; Guan et al., 2013; Ma et al., 2013; Monasterio \& Sarmiento, 1976; Moore et al., 2018). Particularly in savannas, phenology and vegetation growth are influenced by plant composition (i.e., tree and grass fraction covers) and fire seasonality (Guan et al., 2014; Williams et al., 2005).

The light-following relationship is common in tropical forests, where trees have been shown to increase photosynthetic activity throughout the dry season. This decoupling of photosynthesis from precipitation is made possible by the deep-rooted trees, which can obtain water from deep soil layers when shallow soils are dry (Nepstad et al., 1994; Restrepo-Coupe et al., 2013). Thus, soil water storage and adaptive leaf development and demography likely regulate the relationship between precipitation and photosynthetic activity in these regions. Both mechanisms have previously been demonstrated to mediate the relationship between climate and photosynthetic activity in tropical forests (Guan et al., 2015; Restrepo-Coupe et al., 2013; Wu et al., 2016, 2017), and likely play a strong role in our results. For instance, some of these forests' photosynthetic activity peaks happen in the late dry season, months after precipitation declined; similarly, they reach low photosynthetic activity levels in the late wet season months after precipitation has peaked. However, site-specific differences in variables such as soil texture and plant traits also likely contribute to the observed geographical variation in these time lags. Our results suggest that it is important for models to consider mechanisms such as these, which can 

gives high importance to radiation but also uses EVI to calculate the fraction of PAR absorbed by chlorophyll, which helps to improve the representation of the seasonal variation of photosynthetic capacity (Zhang et al., 2017). Among the three models and the two global GPP datasets studied, LPJ-GUESS and VPM showed the closest agreement with our satellite-based results.

Land cover change has undoubtedly influenced the types of relationships observed in SIF and MAIAC EVI. The model output analyzed here uses a static land cover type and could, therefore, misrepresent some of the observed dynamics between climate and SIF and MAIAC EVI. Therefore, we recommend a careful reading of our comparison in regions with high levels of land cover change.

We identified clear, distinct patterns at large spatial and temporal scales in the observed relationships of tropical photosynthetic activity with precipitation and radiation, despite wide physiological, microclimatic and ecological variation. The large-scale nature of this study, at relatively low resolution, necessarily ignores important ecological factors and confounding variables associated with both climate and photosynthetic activity. Nutrient availability, microclimate, topography, soil texture, plant community dynamics, and anthropogenic disturbances are all important factors that influence photosynthetic activity and are not considered here. Yet, the broad spatial patterns identified here can guide research on the predominant mechanistic processes driving photosynthetic activity. Our evaluation of model and GPP products revealed the types of climate-vegetation relationships that are least accurately simulated by models. We expect that our classification of photosynthetic activity relationships will simplify model comparison and benchmarking for tropical ecosystems. Our characterization of the time lags shows the existence and extent of important delayed relationships of photosynthetic activity with each of the climate drivers in specific vegetation types and regions in the tropics. These results should guide modeling and experimental studies about the potential processes that determine seasonality of photosynthetic activity in the tropics. We believe this improved understanding could lead to more realistic predictions of how tropical vegetation will respond to ongoing climate change, with implications for the climate system.

\section{Acknowledgments}

We thank all the research teams that made the data used in this project publicly available. We thank the TRENDY CLM4.5, JULES, and LPJ-GUESS modeling teams for contributing their model output and S. Sitch for making it available for this study. We thank Mary Mulligan for her help with SIF data collection. We thank the Statistical Consulting Service at Purdue University for their assistance with the cross-correlation function analysis.

\section{Data Availability Statement}

Rainfall (TRMM, 2011) and radiation (Loeb et al., 2009) data were downloaded from GES DISC (https://disc.gsfc.nasa.gov/). Temperature data is available through Harris et al. (2014) and can be downloaded from CRU (https://crudata.uea.ac.uk/cru/data/hrg/). The Rainy and Dry Seasons (RADS) dataset is available through Bombardi et al. (2019). SIF data were downloaded from the GDFC data center (https://avdc.gsfc.nasa.gov/pub/data/satellite/MetOp/GOME_F/). The GOSIF dataset is available through Li and Xiao (2019) and can be downloaded from the Global Ecology Group repository (http://data.globalecology.unh.edu/data/GOSIF/). MAIAC EVI data are available through Lyapustin et al. (2018) and can be downloaded from the NCCS Dataportal 
(https://portal.nccs.nasa.gov/datashare/maiac/DataRelease/Global-VI-8day-0.05degree/). Model output from the TRENDY project is available through Sitch et al. (2015).

\section{References}

Bertani, G., Wagner, F. H., Anderson, L. O., \& Aragão, L. E. O. C. (2017). Chlorophyll Fluorescence Data Reveals Climate-Related Photosynthesis Seasonality in Amazonian Forests. Remote Sensing, 9(12), 1275. https://doi.org/10.3390/rs9121275

Best, M. J., Pryor, M., Clark, D. B., Rooney, G. G., Essery, R. L. H., Ménard, C. B., Edwards, J. M., Hendry, M. A., Porson, A., Gedney, N., Mercado, L. M., Sitch, S., Blyth, E., Boucher, O., Cox, P. M., Grimmond, C. S. B., \& Harding, R. J. (2011). The Joint UK Land Environment Simulator (JULES), model description - Part 1: Energy and water fluxes. Geoscientific Model Development, 4(3), 677-699. https://doi.org/10.5194/gmd-4677-2011

Bie, S. D., Ketner, P., Paasse, M., \& Geerling, C. (1998). Woody plant phenology in the West Africa savanna. Journal of Biogeography, 25(5), 883-900. https://doi.org/10.1046/j.1365-2699.1998.00229.x

Bombardi, R. J., Kinter, J. L., \& Frauenfeld, O. W. (2019). A Global Gridded Dataset of the Characteristics of the Rainy and Dry Seasons. Bulletin of the American Meteorological Society. https://doi.org/10.1175/BAMS-D-18-0177.1

Box, G. E. P., Jenkins, G. M., Reinsel, G. C., Ljung, G. M., \& Ljung, G. M. (2015). Time Series Analysis: Forecasting and Control. John Wiley \& Sons, Incorporated. http://ebookcentral.proquest.com/lib/purdue/detail.action?docID=2064681

Bradley, A. V., Gerard, F. F., Barbier, N., Weedon, G. P., Anderson, L. O., Huntingford, C., Aragão, L. E. O. C., Zelazowski, P., \& Arai, E. (2011a). Relationships between phenology, radiation and precipitation in the Amazon region. Global Change Biology, 17(6), 2245-2260. https://doi.org/10.1111/j.1365-2486.2011.02405.x

Bradley, A. V., Gerard, F. F., Barbier, N., Weedon, G. P., Anderson, L. O., Huntingford, C., Aragão, L. E. O. C., Zelazowski, P., \& Arai, E. (2011b). Relationships between phenology, radiation and precipitation in the Amazon region. Global Change Biology, 17(6), 2245-2260. https://doi.org/10.1111/j.1365-2486.2011.02405.x

Chan, K.-S., \& Ripley, B. (2012). TSA: Time Series Analysis. R package version 1.01. https://CRAN.R-project.org/package=TSA

Cohen, J. (1960). A Coefficient of Agreement for Nominal Scales. Educational and Psychological Measurement, 20(1), 37-46. https://doi.org/10.1177/001316446002000104

Cryer, J. D., \& Chan, K.-S. (2008). Time Series Analysis: With Applications in R (2nd ed.). Springer-Verlag. https://doi.org/10.1007/978-0-387-75959-3

Doughty, R., Köhler, P., Frankenberg, C., Magney, T. S., Xiao, X., Qin, Y., Wu, X., \& Moore, B. (2019). TROPOMI reveals dry-season increase of solar-induced chlorophyll fluorescence in the Amazon forest. Proceedings of the National Academy of Sciences, 116(44), 22393-22398. https://doi.org/10.1073/pnas.1908157116

Duff, G. A., Myers, B. A., Williams, R. J., Eamus, D., O’Grady, A., \& Fordyce, I. R. (1997). Seasonal Patterns in Soil Moisture, Vapour Pressure Deficit, Tree Canopy Cover and Predawn Water Potential in a Northern Australian Savanna. Australian Journal of Botany, 45(2), 211-224. https://doi.org/10.1071/bt96018

Dunn, O. J. (1964). Multiple Comparisons Using Rank Sums. Technometrics, 6(3), 241-252. JSTOR. https://doi.org/10.2307/1266041 
Guan, K., Pan, M., Li, H., Wolf, A., Wu, J., Medvigy, D., Caylor, K. K., Sheffield, J., Wood, E. F., Malhi, Y., Liang, M., Kimball, J. S., Saleska, S. R., Berry, J., Joiner, J., \& Lyapustin, A. I. (2015). Photosynthetic seasonality of global tropical forests constrained by hydroclimate. Nature Geoscience, 8(4), 284-289. https://doi.org/10.1038/ngeo2382

Guan, K., Wolf, A., Medvigy, D., Caylor, K. K., Pan, M., \& Wood, E. F. (2013). Seasonal coupling of canopy structure and function in African tropical forests and its environmental controls. Ecosphere, 4(3), art35. https://doi.org/10.1890/ES12-00232.1

Guan, K., Wood, E. F., Medvigy, D., Kimball, J., Pan, M., Caylor, K. K., Sheffield, J., Xu, X., \& Jones, M. O. (2014). Terrestrial hydrological controls on land surface phenology of African savannas and woodlands. Journal of Geophysical Research: Biogeosciences, 119(8), 1652-1669. https://doi.org/10.1002/2013JG002572

Hansen, M. C., Potapov, P. V., Moore, R., Hancher, M., Turubanova, S. A., Tyukavina, A., Thau, D., Stehman, S. V., Goetz, S. J., Loveland, T. R., Kommareddy, A., Egorov, A., Chini, L., Justice, C. O., \& Townshend, J. R. G. (2013). High-Resolution Global Maps of 21st-Century Forest Cover Change. Science, 342(6160), 850-853. https://doi.org/10.1126/science.1244693

Harris, I., Jones, P. D., Osborn, T. J., \& Lister, D. H. (2014). Updated high-resolution grids of monthly climatic observations - the CRU TS3.10 Dataset. International Journal of Climatology, 34(3), 623-642. https://doi.org/10.1002/joc.3711

Huete, A. R., Didan, K., Shimabukuro, Y. E., Ratana, P., Saleska, S. R., Hutyra, L. R., Yang, W., Nemani, R. R., \& Myneni, R. (2006). Amazon rainforests green-up with sunlight in dry season. Geophysical Research Letters, 33(6). https://doi.org/10.1029/2005GL025583

Huffman, G. J., Bolvin, D. T., Nelkin, E. J., Wolff, D. B., Adler, R. F., Gu, G., Hong, Y., Bowman, K. P., \& Stocker, E. F. (2007). The TRMM Multisatellite Precipitation Analysis (TMPA): Quasi-Global, Multiyear, Combined-Sensor Precipitation Estimates at Fine Scales. Journal of Hydrometeorology, 8(1), 38-55. https://doi.org/10.1175/JHM560.1

Hyndman, R. (2017). _forecast: Forecasting functions for time series and linear models_. $R$ package version 8.2 . http://pkg.robjhyndman.com/forecast

Joiner, J., Guanter, L., Lindstrot, R., Voigt, M., Vasilkov, A. P., Middleton, E. M., Huemmrich, K. F., Yoshida, Y., \& Frankenberg, C. (2013). Global monitoring of terrestrial chlorophyll fluorescence from moderate-spectral-resolution near-infrared satellite measurements: Methodology, simulations, and application to GOME-2. Atmospheric Measurement Techniques, 6(10), 2803-2823. https://doi.org/10.5194/amt-6-2803-2013

Joiner, J., Yoshida, Y., Vasilkov, A. P., Schaefer, K., Jung, M., Guanter, L., Zhang, Y., Garrity, S., Middleton, E. M., Huemmrich, K. F., Gu, L., \& Belelli Marchesini, L. (2014). The seasonal cycle of satellite chlorophyll fluorescence observations and its relationship to vegetation phenology and ecosystem atmosphere carbon exchange. Remote Sensing of Environment, 152, 375-391. https://doi.org/10.1016/j.rse.2014.06.022

Joiner, J., Yoshida, Y., Vasilkov, A. P., Yoshida, Y., Corp, L. A., \& Middleton, E. M. (2011). First observations of global and seasonal terrestrial chlorophyll fluorescence from space. Biogeosciences, 8(3), 637-651. https://doi.org/10.5194/bg-8-637-2011

Jung, M., \& Team, F. (2016). FLUXCOM (RS+METEO) Global Land Carbon Fluxes using CRUNCEP climate data [Data set]. https://doi.org/10.17871/fluxcom_rs_meteo_cruncepv6_1980_2013_v1 
Kato, S., Loeb, N. G., Rose, F. G., Doelling, D. R., Rutan, D. A., Caldwell, T. E., Yu, L., \& Weller, R. A. (2013). Surface Irradiances Consistent with CERES-Derived Top-ofAtmosphere Shortwave and Longwave Irradiances. Journal of Climate, 26(9), 27192740. https://doi.org/10.1175/JCLI-D-12-00436.1

Kruskal, W. H., \& Wallis, W. A. (1952). Use of Ranks in One-Criterion Variance Analysis. Journal of the American Statistical Association, 47(260), 583-621. JSTOR. https://doi.org/10.2307/2280779

Lawrence, D., \& Vandecar, K. (2015). Effects of tropical deforestation on climate and agriculture. Nature Climate Change, 5(1), 27-36. https://doi.org/10.1038/nclimate2430

Li, X., \& Xiao, J. (2019). A Global, 0.05-Degree Product of Solar-Induced Chlorophyll Fluorescence Derived from OCO-2, MODIS, and Reanalysis Data. Remote Sensing, 11(5), 517. https://doi.org/10.3390/rs11050517

Loeb, N. G., B. A. Wielicki, D. R. Doelling, G. L. Smith, D. F. Keyes, S. Kato, N. ManaloSmith, T. Wong, 2009: Toward optimal closure of the Earth's top-of-atmosphere radiation budget. J . Climate, 22, 748-766, doi:10.1175/2008JCLI2637.1.

Lyapustin, A. I., Wang, Y., Laszlo, I., Hilker, T., G.Hall, F., Sellers, P. J., Tucker, C. J., \& Korkin, S. V. (2012). Multi-angle implementation of atmospheric correction for MODIS (MAIAC): 3. Atmospheric correction. Remote Sensing of Environment, 127, 385-393. https://doi.org/10.1016/j.rse.2012.09.002

Lyapustin, A., Wang, Y., Korkin, S., \& Huang, D. (2018). MODIS Collection 6 MAIAC algorithm. Atmospheric Measurement Techniques, 11(10), 5741-5765. https://doi.org/10.5194/amt-11-5741-2018

Ma, X., Huete, A., Yu, Q., Coupe, N. R., Davies, K., Broich, M., Ratana, P., Beringer, J., Hutley, L. B., Cleverly, J., Boulain, N., \& Eamus, D. (2013). Spatial patterns and temporal dynamics in savanna vegetation phenology across the North Australian Tropical Transect. Remote Sensing of Environment, 139, 97-115. https://doi.org/10.1016/j.rse.2013.07.030

Maeda, E. E., Moura, Y. M., Wagner, F., Hilker, T., Lyapustin, A. I., Wang, Y., Chave, J., Mõttus, M., Aragão, L. E. O. C., \& Shimabukuro, Y. (2016). Consistency of vegetation index seasonality across the Amazon rainforest. International Journal of Applied Earth Observation and Geoinformation, 52, 42-53. https://doi.org/10.1016/j.jag.2016.05.005

Malhi, Y., Roberts, J. T., Betts, R. A., Killeen, T. J., Li, W., \& Nobre, C. A. (2008). Climate Change, Deforestation, and the Fate of the Amazon. Science, 319(5860), 169-172. https://doi.org/10.1126/science.1146961

Mitchard, E. T. A. (2018). The tropical forest carbon cycle and climate change. Nature, 559(7715), 527. https://doi.org/10.1038/s41586-018-0300-2

Monasterio, M., \& Sarmiento, G. (1976). Phenological Strategies of Plant Species in the Tropical Savanna and the Semi-Deciduous Forest of the Venezuelan Llanos. Journal of Biogeography, 3(4), 325-355. JSTOR. https://doi.org/10.2307/3037976

Moore, C. E., Beringer, J., Donohue, R. J., Evans, B., Exbrayat, J.-F., Hutley, L. B., \& Tapper, N. J. (2018). Seasonal, interannual and decadal drivers of tree and grass productivity in an Australian tropical savanna. Global Change Biology, 24(6), 2530-2544. https://doi.org/10.1111/gcb.14072

Myneni, R. B., Yang, W., Nemani, R. R., Huete, A. R., Dickinson, R. E., Knyazikhin, Y., Didan, K., Fu, R., Juárez, R. I. N., Saatchi, S. S., Hashimoto, H., Ichii, K., Shabanov, N. V., Tan, B., Ratana, P., Privette, J. L., Morisette, J. T., Vermote, E. F., Roy, D. P., ... Salomonson, 
V. V. (2007). Large seasonal swings in leaf area of Amazon rainforests. Proceedings of the National Academy of Sciences, 104(12), 4820-4823.

https://doi.org/10.1073/pnas.0611338104

Nemani, R. R., Keeling, C. D., Hashimoto, H., Jolly, W. M., Piper, S. C., Tucker, C. J., Myneni, R. B., \& Running, S. W. (2003). Climate-Driven Increases in Global Terrestrial Net Primary Production from 1982 to 1999. Science, 300(5625), 1560-1563. https://doi.org/10.1126/science.1082750

Nepstad, D. C., de Carvalho, C. R., Davidson, E. A., Jipp, P. H., Lefebvre, P. A., Negreiros, G. H., da Silva, E. D., Stone, T. A., Trumbore, S. E., \& Vieira, S. (1994). The role of deep roots in the hydrological and carbon cycles of Amazonian forests and pastures. Nature, 372(6507), 666-669.

Ogle, D. H., Wheeler, P., \& Dinno, A. (2018). FSA: Fisheries Stock Analysis. R package version 0.8.22. https://github.com/droglenc/FSA

Oleson, K., Lawrence, M., Bonan, B., Drewniak, B., Huang, M., Koven, D., Levis, S., Li, F., Riley, J., Subin, M., Swenson, S., Thornton, E., Bozbiyik, A., Fisher, R., Heald, L., Kluzek, E., Lamarque, J.-F., Lawrence, J., Leung, R., ... Yang, Z.-L. (2013). Technical description of version 4.5 of the Community Land Model (CLM). https://doi.org/10.5065/D6RR1W7M

Pontius Jr., R. G., \& Santacruz, A. (2019). DiffeR: Metrics of Difference for Comparing Pairs of Maps or Pairs of Variables (R package version 0.0-6) [Computer software]. https://CRAN.R-project.org/package=diffeR

Pontius, R. G., \& Santacruz, A. (2014). Quantity, exchange, and shift components of difference in a square contingency table. International Journal of Remote Sensing, 35(21), 75437554. https://doi.org/10.1080/2150704X.2014.969814

Poulter, B., Heyder, U., \& Cramer, W. (2009). Modeling the Sensitivity of the Seasonal Cycle of GPP to Dynamic LAI and Soil Depths in Tropical Rainforests. Ecosystems, 12(4), 517533. https://doi.org/10.1007/s10021-009-9238-4

Probst, W. N., Stelzenmüller, V., \& Fock, H. O. (2012). Using cross-correlations to assess the relationship between time-lagged pressure and state indicators: An exemplary analysis of North Sea fish population indicators. ICES Journal of Marine Science, 69(4), 670-681. https://doi.org/10.1093/icesjms/fss015

R Core Team. (2017). R: A language and environment for statistical computing. R Foundation for Statistical Computing, Vienna, Austria. https://www.R-project.org/

Restrepo-Coupe, N., da Rocha, H. R., Hutyra, L. R., da Araujo, A. C., Borma, L. S., Christoffersen, B., Cabral, O. M. R., de Camargo, P. B., Cardoso, F. L., da Costa, A. C. L., Fitzjarrald, D. R., Goulden, M. L., Kruijt, B., Maia, J. M. F., Malhi, Y. S., Manzi, A. O., Miller, S. D., Nobre, A. D., von Randow, C., ... Saleska, S. R. (2013). What drives the seasonality of photosynthesis across the Amazon basin? A cross-site analysis of eddy flux tower measurements from the Brasil flux network. Agricultural and Forest Meteorology, 182-183, 128-144. https://doi.org/10.1016/j.agrformet.2013.04.031

Restrepo-Coupe, N., Levine, N. M., Christoffersen, B. O., Albert, L. P., Wu, J., Costa, M. H., Galbraith, D., Imbuzeiro, H., Martins, G., Araujo, A. C. da, Malhi, Y. S., Zeng, X., Moorcroft, P., \& Saleska, S. R. (2017). Do dynamic global vegetation models capture the seasonality of carbon fluxes in the Amazon basin? A data-model intercomparison. Global Change Biology, 23(1), 191-208. https://doi.org/10.1111/gcb.13442 
Rivera, G., Elliott, S., Caldas, L. S., Nicolossi, G., Coradin, V. T., \& Borchert, R. (2002). Increasing day-length induces spring flushing of tropical dry forest trees in the absence of rain. Trees, 16(7), 445-456. https://doi.org/10.1007/s00468-002-0185-3

Saigusa, N., Yamamoto, S., Hirata, R., Ohtani, Y., Ide, R., Asanuma, J., Gamo, M., Hirano, T., Kondo, H., Kosugi, Y., Li, S.-G., Nakai, Y., Takagi, K., Tani, M., \& Wang, H. (2008). Temporal and spatial variations in the seasonal patterns of $\mathrm{CO} 2$ flux in boreal, temperate, and tropical forests in East Asia. Agricultural and Forest Meteorology, 148(5), 700-713. https://doi.org/10.1016/j.agrformet.2007.12.006

Saleska, S. R., Miller, S. D., Matross, D. M., Goulden, M. L., Wofsy, S. C., da Rocha, H. R., de Camargo, P. B., Crill, P., Daube, B. C., de Freitas, H. C., Hutyra, L., Keller, M., Kirchhoff, V., Menton, M., Munger, J. W., Pyle, E. H., Rice, A. H., \& Silva, H. (2003). Carbon in Amazon Forests: Unexpected Seasonal Fluxes and Disturbance-Induced Losses. Science, 302(5650), 1554-1557. JSTOR.

Seddon, A. W. R., Macias-Fauria, M., Long, P. R., Benz, D., \& Willis, K. J. (2016). Sensitivity of global terrestrial ecosystems to climate variability. Nature, 531(7593), 229-232. https://doi.org/10.1038/nature16986

Sen, O. L., Bozkurt, D., Vogler, J. B., Fox, J., Giambelluca, T. W., \& Ziegler, A. D. (2013). Hydro-climatic effects of future land-cover/land-use change in montane mainland southeast Asia. Climatic Change; Dordrecht, 118(2), 213-226. http://dx.doi.org.ezproxy.lib.purdue.edu/10.1007/s10584-012-0632-0

Sitch, S., Friedlingstein, P., Gruber, N., Jones, S. D., Murray-Tortarolo, G., Ahlström, A., Doney, S. C., Graven, H., Heinze, C., Huntingford, C., Levis, S., Levy, P. E., Lomas, M., Poulter, B., Viovy, N., Zaehle, S., Zeng, N., Arneth, A., Bonan, G., ... Myneni, R. (2015). Recent trends and drivers of regional sources and sinks of carbon dioxide. Biogeosciences, 12(3), 653-679. https://doi.org/10.5194/bg-12-653-2015

Smith, B., Prentice, I. C., \& Sykes, M. T. (2001). Representation of Vegetation Dynamics in the Modelling of Terrestrial Ecosystems: Comparing Two Contrasting Approaches within European Climate Space. Global Ecology and Biogeography, 10(6), 621-637. JSTOR.

Tramontana, G., Jung, M., Schwalm, C. R., Ichii, K., Camps-Valls, G., Ráduly, B., Reichstein, M., Arain, M. A., Cescatti, A., Kiely, G., Merbold, L., Serrano-Ortiz, P., Sickert, S., Wolf, S., \& Papale, D. (2016). Predicting carbon dioxide and energy fluxes across global FLUXNET sites with regression algorithms. Biogeosciences, 13(14), 4291-4313. https://doi.org/10.5194/bg-13-4291-2016

Tropical Rainfall Measuring Mission (TRMM) (2011), TRMM (TMPA/3B43) Rainfall Estimate L3 1 month 0.25 degree x 0.25 degree V7, Greenbelt, MD, Goddard Earth Sciences Data and Information Services Center (GES DISC), Accessed February 2018, 10.5067/TRMM/TMPA/MONTH/7

Wagner, F. H., Hérault, B., Rossi, V., Hilker, T., Maeda, E. E., Sanchez, A., Lyapustin, A. I., Galvão, L. S., Wang, Y., \& Aragão, L. E. O. C. (2017). Climate drivers of the Amazon forest greening. PLOS ONE, 12(7), e0180932. https://doi.org/10.1371/journal.pone.0180932

Walsh, R. P. D., \& Lawler, D. M. (1981). Rainfall Seasonality: Description, Spatial Patterns and Change Through Time. Weather, 36(7), 201-208. https://doi.org/10.1002/j.14778696.1981.tb05400.x 
Williams, P. R., Congdon, R. A., Grice, A. C., \& Clarke, P. J. (2005). Germinable soil seed banks in a tropical savanna: Seasonal dynamics and effects of fire. Austral Ecology, 30(1), 79-90. https://doi.org/10.1111/j.1442-9993.2004.01426.x

Wu, D., Zhao, X., Liang, S., Zhou, T., Huang, K., Tang, B., \& Zhao, W. (2015). Time-lag effects of global vegetation responses to climate change. Global Change Biology, 21(9), 35203531. https://doi.org/10.1111/gcb.12945

Wu, J., Albert, L. P., Lopes, A. P., Restrepo-Coupe, N., Hayek, M., Wiedemann, K. T., Guan, K., Stark, S. C., Christoffersen, B., Prohaska, N., Tavares, J. V., Marostica, S., Kobayashi, H., Ferreira, M. L., Campos, K. S., Silva, R. da, Brando, P. M., Dye, D. G., Huxman, T. E., ... Saleska, S. R. (2016). Leaf development and demography explain photosynthetic seasonality in Amazon evergreen forests. Science, 351(6276), 972-976. https://doi.org/10.1126/science.aad5068

Wu, J., Serbin, S. P., Xu, X., Albert, L. P., Chen, M., Meng, R., Saleska, S. R., \& Rogers, A. (2017). The phenology of leaf quality and its within-canopy variation is essential for accurate modeling of photosynthesis in tropical evergreen forests. Global Change Biology, 23(11), 4814-4827. https://doi.org/10.1111/gcb.13725

Xu, L., Saatchi, S. S., Yang, Y., Myneni, R. B., Frankenberg, C., Chowdhury, D., \& Bi, J. (2015). Satellite observation of tropical forest seasonality: Spatial patterns of carbon exchange in Amazonia. Environmental Research Letters, 10(8), 084005. https://doi.org/10.1088/1748-9326/10/8/084005

Zhang, Y., Joiner, J., Gentine, P., \& Zhou, S. (2018). Reduced solar-induced chlorophyll fluorescence from GOME-2 during Amazon drought caused by dataset artifacts. Global Change Biology, 24(6), 2229-2230. https://doi.org/10.1111/gcb.14134

Zhang, Y., Xiao, X., Wu, X., Zhou, S., Zhang, G., Qin, Y., \& Dong, J. (2017). A global moderate resolution dataset of gross primary production of vegetation for 2000-2016. Scientific Data, 4, 170165. https://doi.org/10.1038/sdata.2017.165 